\title{
Third retransplantation using a whole liver graft for late graft failure from hepatic vein stent stenosis in a pediatric patient who underwent split liver retransplantation
}

\author{
Jung-Man Namgoong ${ }^{1}$, Shin Hwang ${ }^{1}$, Young-In Yoon ${ }^{1}$, Yong-Pil Cho', Woo-Hyoung Kang ${ }^{1}$, \\ Yong Jae Kwon ${ }^{1}$, Hyunhee Kwon ${ }^{1}$, Sang Hoon Kim', Kyung Mo Kim², and Seak Hee $\mathrm{Oh}^{2}$
}

Departments of ${ }^{1}$ Surgery and ${ }^{2}$ Pediatrics, Asan Medical Center, University of Ulsan College of Medicine, Seoul, Korea

\begin{abstract}
We present a case of third retransplantation using a whole liver graft in a 13-year-old girl who suffered graft failure and hepatopulmonary syndrome following split liver retransplantation with endovascular stenting of the hepatic and portal veins as an infant. She was diagnosed with biliary atresia-polysplenia syndrome, and thus underwent living donor liver transplantation from her mother at 9 months of age. The first liver graft failed due to stenosis of the portal vein. She underwent the second liver transplantation with a split left lateral section graft. Endovascular stenting was performed to the portal vein stenosis 2 months and hepatic vein stenosis 9 months after transplantation. During the next 9 years, 11 sessions of balloon angioplasty for hepatic vein stent stenosis were performed. Ten years after the second transplantation, she underwent third transplantation using a whole liver graft recovered from a 12 -year-old-girl. The double inferior vena cava technique was used for outflow vein reconstruction. The graft portal vein was anastomosed with the stent-containing portal vein stump because it was not possible to remove the stent and the inner diameter of the portal vein stent was large enough. An aorto-hepatic jump graft was used for arterial reconstruction. The patient recovered slowly and is doing well for 6 months posttransplant. In conclusion, because stenting of the hepatic vein or portal vein can induce graft failure leading to late retransplantation, we emphasize secure vascular reconstruction to prevent endovascular stenting during LT in infants. (Ann Hepatobiliary Pancreat Surg 2021;25:299-306)
\end{abstract}

Key Words: Hepatic vein stenosis; Portal vein stenosis; Endovascular stenting; Vascular insufficiency; Infant

\section{INTRODUCTION}

Pediatric liver transplantation (LT) in infant recipients requires special attention to vascular reconstruction because the small-sized vessels of the grafts and recipients make them vulnerable to various vascular complications. Endovascular stenting can be a life-saving procedure following LT, but it cannot be a definitive treatment in infant recipients because a wall stent may not be expanded enough to accommodate the long-term physical growth from infant through adolescence and adulthood. ${ }^{1}$ It is difficult to treat stent-associated hepatic or portal vein stenosis through percutaneous angioplasty. ${ }^{2-6}$ As a result, endovascular stenting performed in infants can cause intractable vascular insufficiency, which can lead to progressive graft liver failure and late retransplantation. We present a case of third retransplantation using a whole liver graft in a pediatric patient who had suffered graft failure following split liver retransplantation with endovascular stenting of the hepatic and portal veins.

\section{CASE}

The patient was a 13-year-old girl who suffered from graft failure following liver retransplantation. This patient had undergone Kasai portoenterostomy 2 months after birth due to biliary atresia. She had a preduodenal portal vein and intestinal malrotation, thus was diagnosed with biliary atresia-polysplenia syndrome. She had been admitted to the hospital repeatedly due to cholangitis and had

Received: January 10, 2021; Revised: January 21, 2021; Accepted: January 23, 2021

Corresponding author: Shin Hwang

Department of Surgery, Asan Medical Center, University of Ulsan College of Medicine, 88 Olympic-ro 43-gil, Songpa-gu, Seoul 05505, Korea Tel: +82-2-3010-3930, Fax: +82-2-3010-6701, E-mail: shwang@amc.seoul.kr

Copyright (C) 2021 by The Korean Association of Hepato-Biliary-Pancreatic Surgery

This is an Open Access article distributed under the terms of the Creative Commons Attribution Non-Commercial License (http://creativecommons.org/ licenses/by-nc/4.0) which permits unrestricted non-commercial use, distribution, and reproduction in any medium, provided the original work is properly cited. Annals of Hepato-Biliary-Pancreatic Surgery • pISSN: 2508-5778 - elSSN: 2508-5859 
undergone percutaneous transhepatic biliary drainage (Fig. 1A).

At the age of 9 months, she underwent living donor liver transplantation (LDLT) using a left lateral section graft from her mother (Fig. 1B). The patient recovered uneventfully from the LDLT operation although the hepatic vein and portal vein anastomoses appeared stenotic (Fig. 1C). Four months after LDLT, she experienced moderate acute rejection and Epstein-Barr virus infection. Thereafter, liver function progressively deteriorated with severe portal vein stenosis and collateral vessel formation. She was diagnosed with hepatopulmonary syndrome grade III. She was put on the waitlist for pediatric deceased donor liver transplantation (DDLT).

At the age of 16 months, 7 months after LDLT, she underwent the second LT using a split left lateral section graft. The pathology report of the explant liver showed fibrous intimal thickening with luminal narrowing of the hilar portal vein, portal bile duct atrophy or loss, and portal fibrosis, which was consistent with portal vein stenosis (Fig. 1D). However, after the second LT, portal vein stenosis persisted (Fig. 2A, B). Two months after the second LT, because severe portal vein stenosis was not cor- rected by balloon angioplasty, a wall stent of $10 \mathrm{~mm} \times 40$ mm was inserted (Fig. 2C, D). Eight months after the second LT, deterioration of liver function with massive ascites occurred (Fig. 3A). A liver biopsy showed marked perivenular congestion with atrophy of the hepatocytes, consistent with hemodynamic derangement. Nine months after the second LT, hepatic vein stenosis with thrombus formation was identified (Fig. 3B), thus mechanical thrombolysis with insertion of wall stents of $8 \mathrm{~mm} \times 40 \mathrm{~mm}$ and $8 \mathrm{~mm} \times 60 \mathrm{~mm}$ was performed (Fig. 3C, D). Thereafter, liver function improved and ascites was controlled. Two years later, hepatic vein stenosis occurred again and balloon angioplasty was performed (Fig. 4). In the subsequent 9 years, 11 sessions of balloon angioplasty were performed to treat the stent-associated hepatic vein stenosis.

At the age of 13 years, 10 years after the second LT, the patient was admitted due to hepatopulmonary syndrome grade IV and hematemesis probably from esophageal varix (Fig. 5A-C). After 3 days on the wait list, she was allocated for DDLT with a whole liver graft from a marginal 12-year-old female donor.

During the recipient operation, the enlarged liver was meticulously dissected due to very heavy adhesions. The
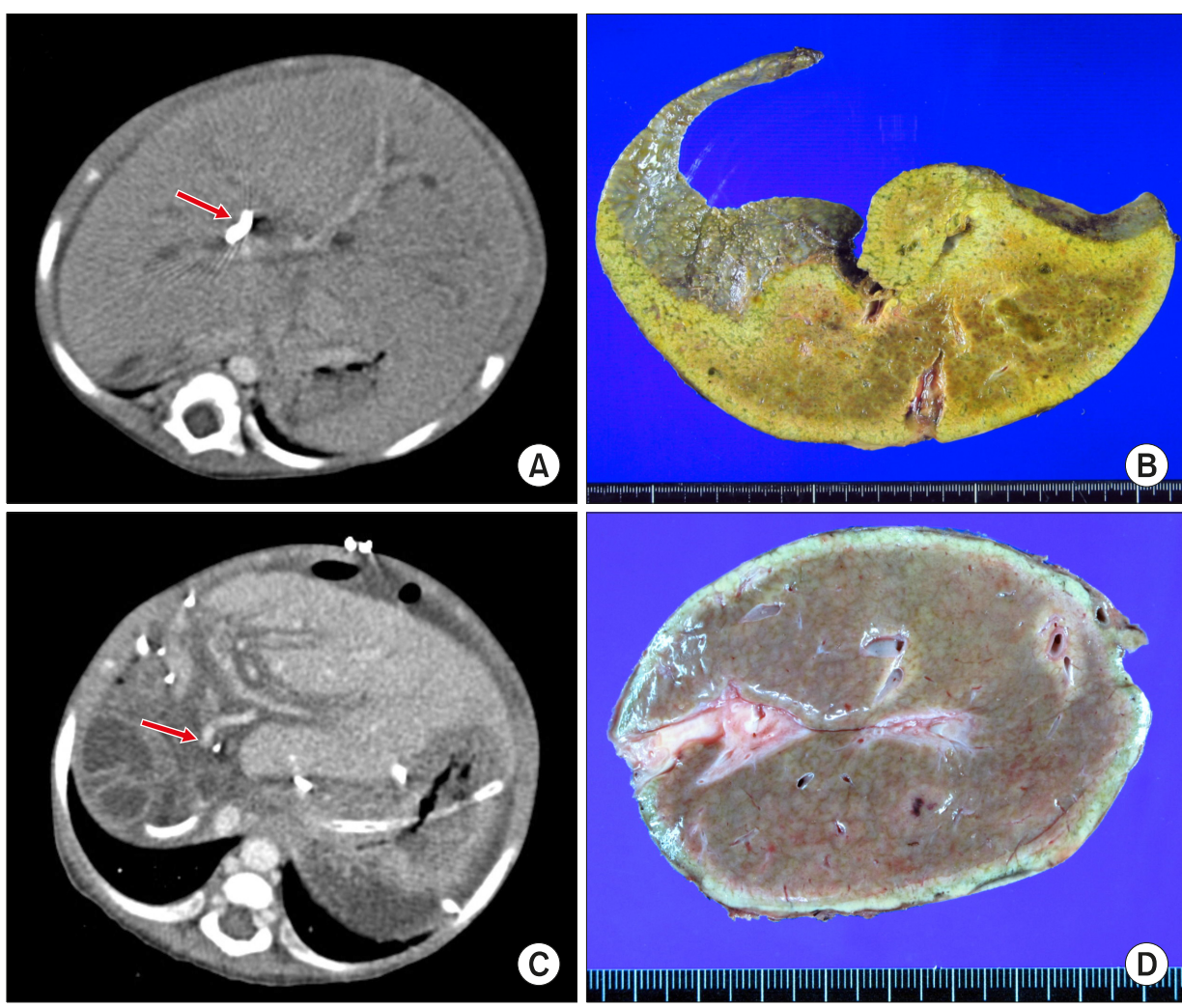

Fig. 1. Findings of the first liver transplantation. (A) Computed tomography taken before the first transplantation shows biliary atresia-polysplenia syndrome with insertion of percutaneous transhepatic biliary drainage (arrow). (B) The explanted native liver taken after the first transplantation is visible. (C) Computed tomography taken 2 weeks after the first transplantation shows the small-sized portal vein (arrow). (D) The explanted first liver graft after the second transplantation is visible. 

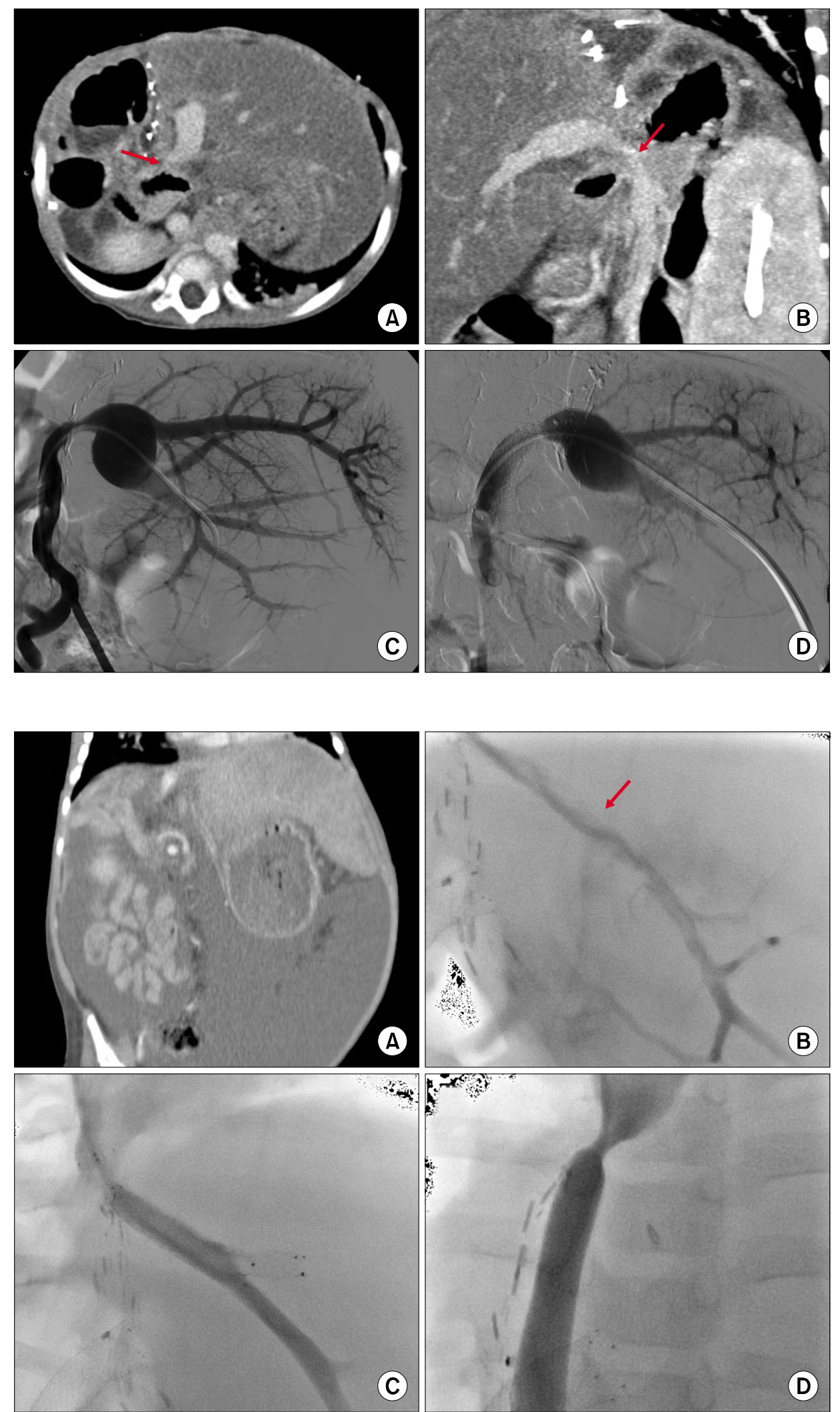

Fig. 2. Findings showing portal vein stenosis after the second liver transplantations. (A, B) Computed tomography taken 1 month after transplantation shows portal vein stenosis (arrows). (C, D) Balloon angioplasty and endovascular stenting with a stent of $10 \mathrm{~mm} \times 40 \mathrm{~mm}$ are performed 2 months after transplantation.

Fig. 3. Findings showing hepatic vein stenosis after the second liver transplantation. (A) Computed tomography taken 8 months after transplantation shows massive ascites. (B) Thrombus (arrow) within the graft hepatic vein is visible. (C, D) Endovascular stenting with stents of $8 \mathrm{~mm} \times 40 \mathrm{~mm}$ and $8 \mathrm{~mm} \times 60$ $\mathrm{mm}$ is performed at 9 months after transplantation.

hepatic hilum, including the portal vein stent, was isolated initially, and the left hepatic artery was transected at the graft level. After temporary clamping the portal vein to prevent bleeding from the dissected liver surface, the liver graft was mobilized extensively. After isolation of the retrohepatic inferior vena cava (IVC), we recognized that the 

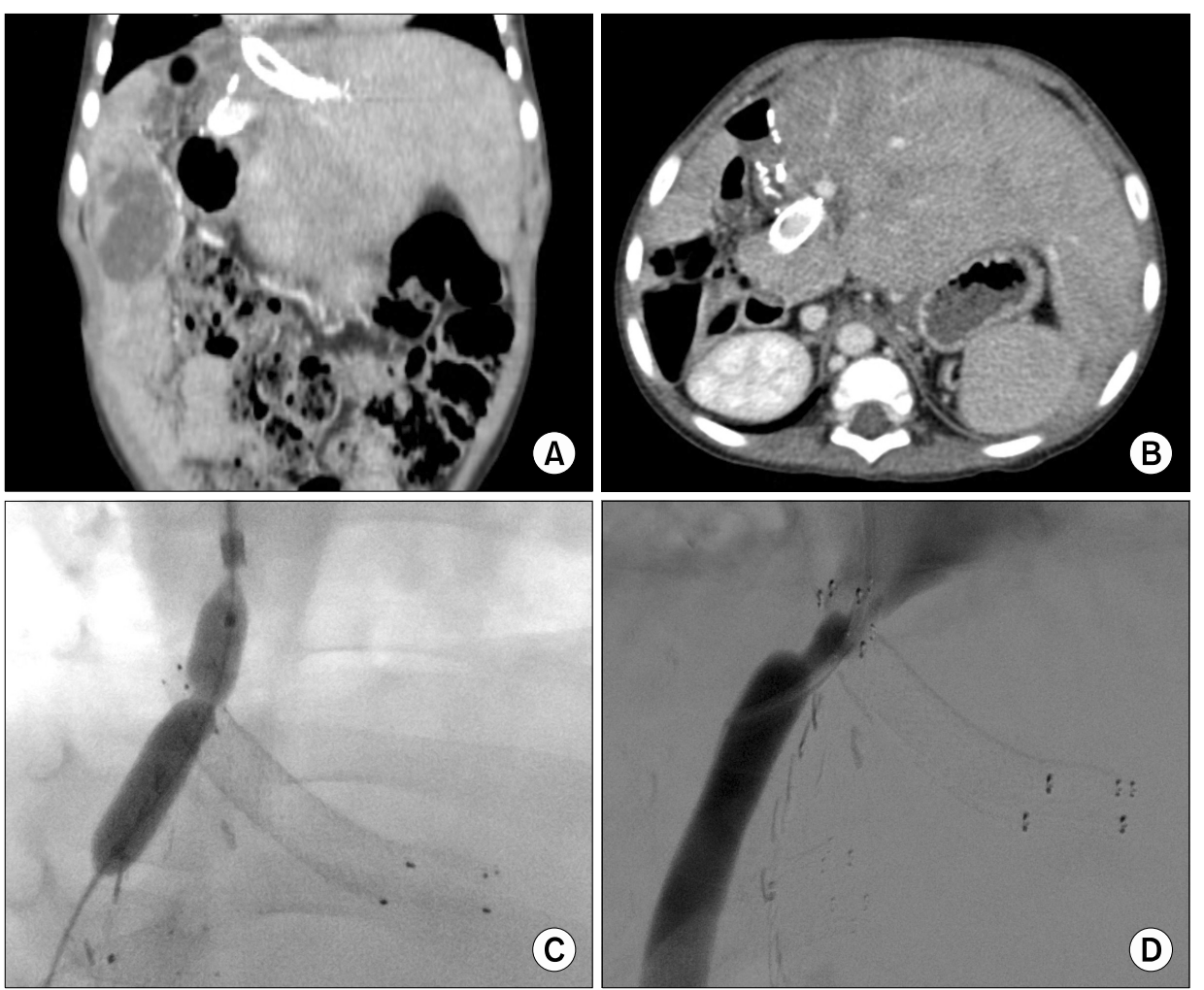

Fig. 4. Findings showing persistent hepatic vein stenosis after the second liver transplantation. (A, B) Computed tomography taken 3 years after transplantation shows hepatic vein and portal vein stenting. $(\mathrm{C}, \mathrm{D})$ The stenotic portions at the hepatic vein stents are dilated through balloon angioplasty.
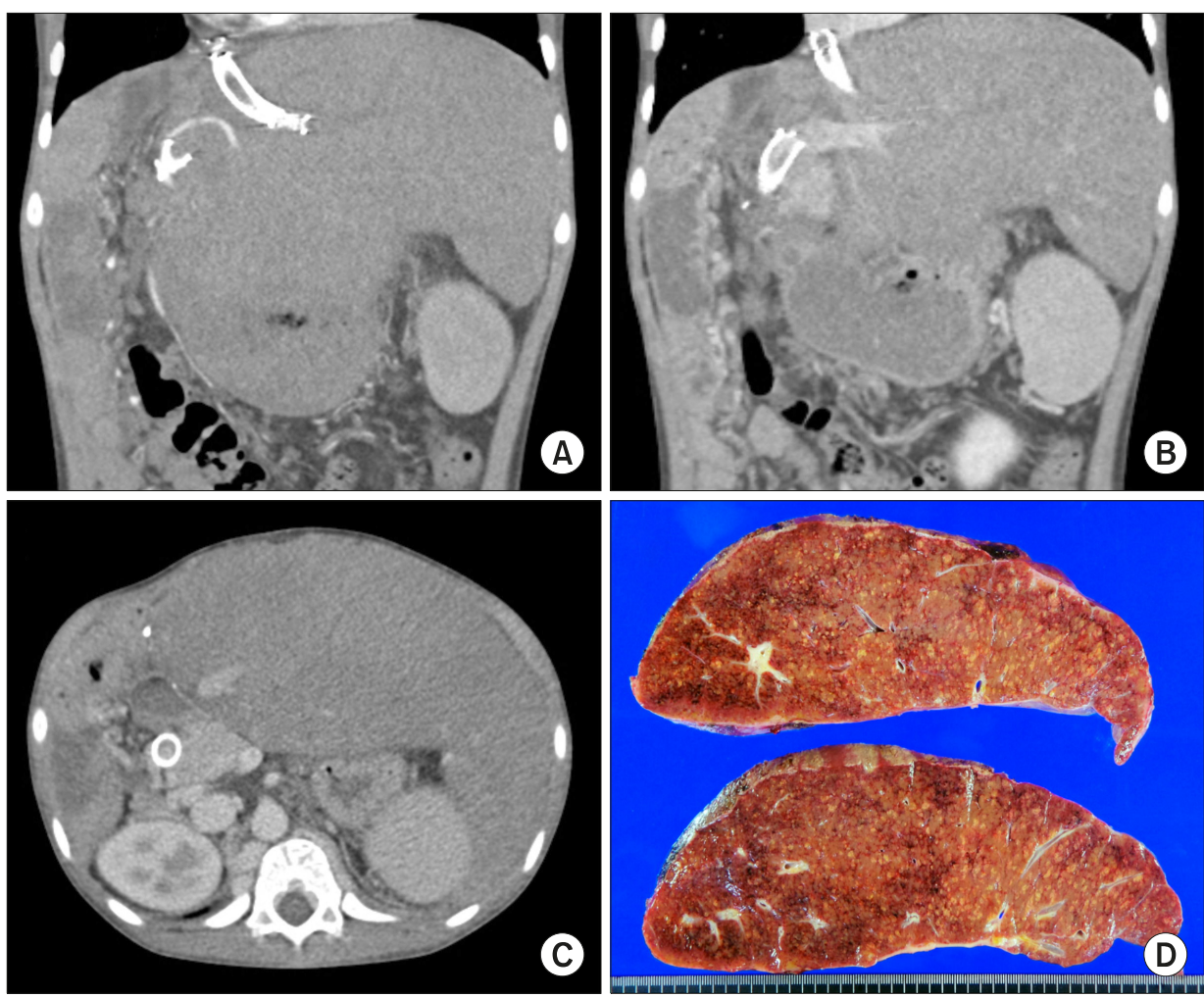

Fig. 5. Findings before the third liver transplantation. (A-C) Computed tomography 4 months before the third transplantation shows marked hepatomegaly with development of collaterals. (D) The explanted second liver graft after the third transplantation is visible.

graft hepatic vein stump could not be used for outflow vein reconstruction because it was markedly stenotic and separate from the retrohepatic IVC, so we dissected the retrohepatic IVC extensively in preparation for double IVC reconstruction.

Because we intended to remove the portal vein stent, 
we extensively dissected the superior mesenteric vein and adjacent collateral veins to isolate the stent-inserted preduodenal portal vein-superior mesenteric vein junction portion. However, after transecting the stent-containing portal vein, we found that the wall stent was heavily adhered to the portal vein wall, making it impossible to remove the portal vein stent (Fig. 6A). Because the wall stent was fully expanded with smoothly-formed neointima
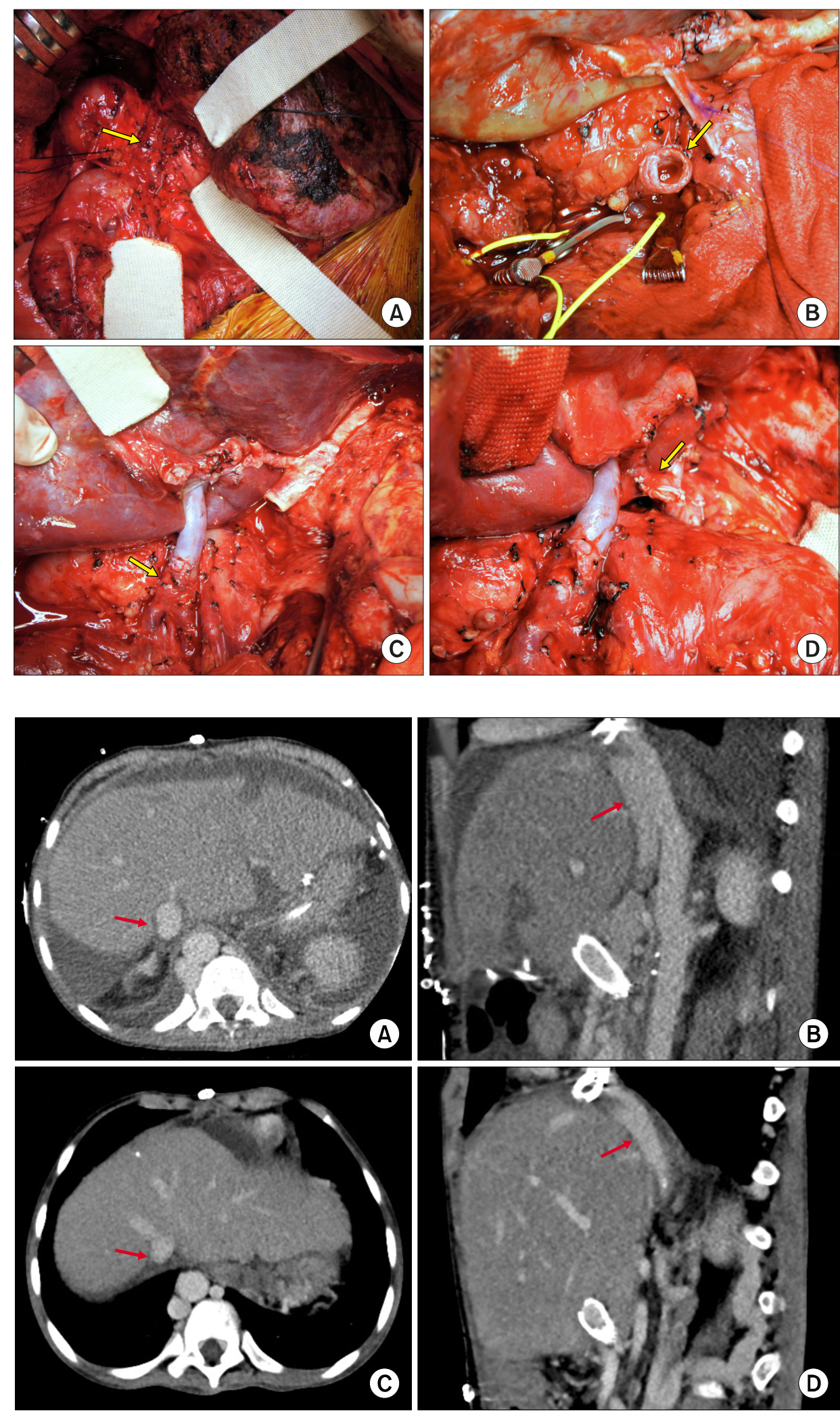

Fig. 6. Intraoperative photographs of the third liver transplantation. (A) The dissected portal vein containing a wall stent is visible (arrow). (B) The transected portal vein shows the lumen of the fully expanded stent with smoothly-formed neointima (arrow). (C) The graft portal vein is anastomosed with the stent-containing portal vein stump (arrow). (D) The graft hepatic artery is reconstructed using a jump graft with an iliac artery graft (arrow).

Fig. 7. Finding of the inferior vena cava reconstruction following the third liver transplantation. (A, B) Computed tomography taken 3 days after third transplantation shows the cavocaval anastomosis (arrows) using a double inferior vena cava technique. $(\mathrm{C}, \mathrm{D})$ Computed tomography taken 1 month after the third transplantation shows the reshaping of the cavocaval anastomosis (arrows), which is similar to the natural smooth streamlined configuration of the double inferior vena cava. 
and its diameter was much larger than the graft portal vein and recipient superior mesenteric vein (Fig. 6B), we decided to use the stent-containing portion for portal vein anastomosis.

The distal end of the graft IVC was closed at the back table. A 4-cm-long incision was made from the upper dorsal part of the graft IVC, thus making a triangular IVC orifice. The suprahepatic end of the graft IVC was partially closed to make a 4-cm-long elliptical opening at the dorsal wall of the retrohepatic IVC.

The recipient's stent-containing portal vein was transected. Then, the stent-containing graft hepatic vein stump was transected and securely closed. After elliptical excision of the anterior wall of the recipient IVC, which was matched with the graft IVC opening, double IVC reconstruction was performed using 5-0 PDS (Fig. 7). The graft portal vein was anastomosed with the stent-containing portal vein stump (Fig. 6C). The blood flow from the native left hepatic artery was weak, thus aorto-hepatic jump graft was performed using an iliac artery allograft (Fig. 6D). Intraoperative portogram was taken via the inferior mesenteric vein, revealing portal vein flow to be well maintained (Fig. 8). Biliary reconstruction was performed using the preformed Roux-en-Y jejunal limb. Because the upper abdominal cavity was too narrow to accommodate the whole liver graft, the transverse abdominal wound was temporarily closed with a xenograft patch. Seven days later, the patch was removed and the abdominal wound was closed.

The pathology report of the explanted second liver graft showed diffuse perivenular hepatocyte dropout and congestion, focal atrophic change of the bile duct with mild ductular proliferation, and bridging and perisinusoidal fibrosis, consistent with hemodynamic derangement (Fig. 5D).

Graft liver function was recovered uneventfully without vascular complications, but overall posttransplant recovery of the general condition was delayed primarily due to prolonged ventilatory support for hepatopulmonary syndrome. The patient was discharged from the hospital at 40 days after transplantation. Currently, she has been doing well for 6 months posttransplant.

\section{DISCUSSION}

Infant recipients undergoing LT are vulnerable to vascular complications, because the graft and recipient vessels are small and an endovascular stenting procedure cannot be a definitive treatment. Once vascular anastomotic stenosis occurs, it is not easily treated through the use of percutaneous radiological angioplasty, because the con-
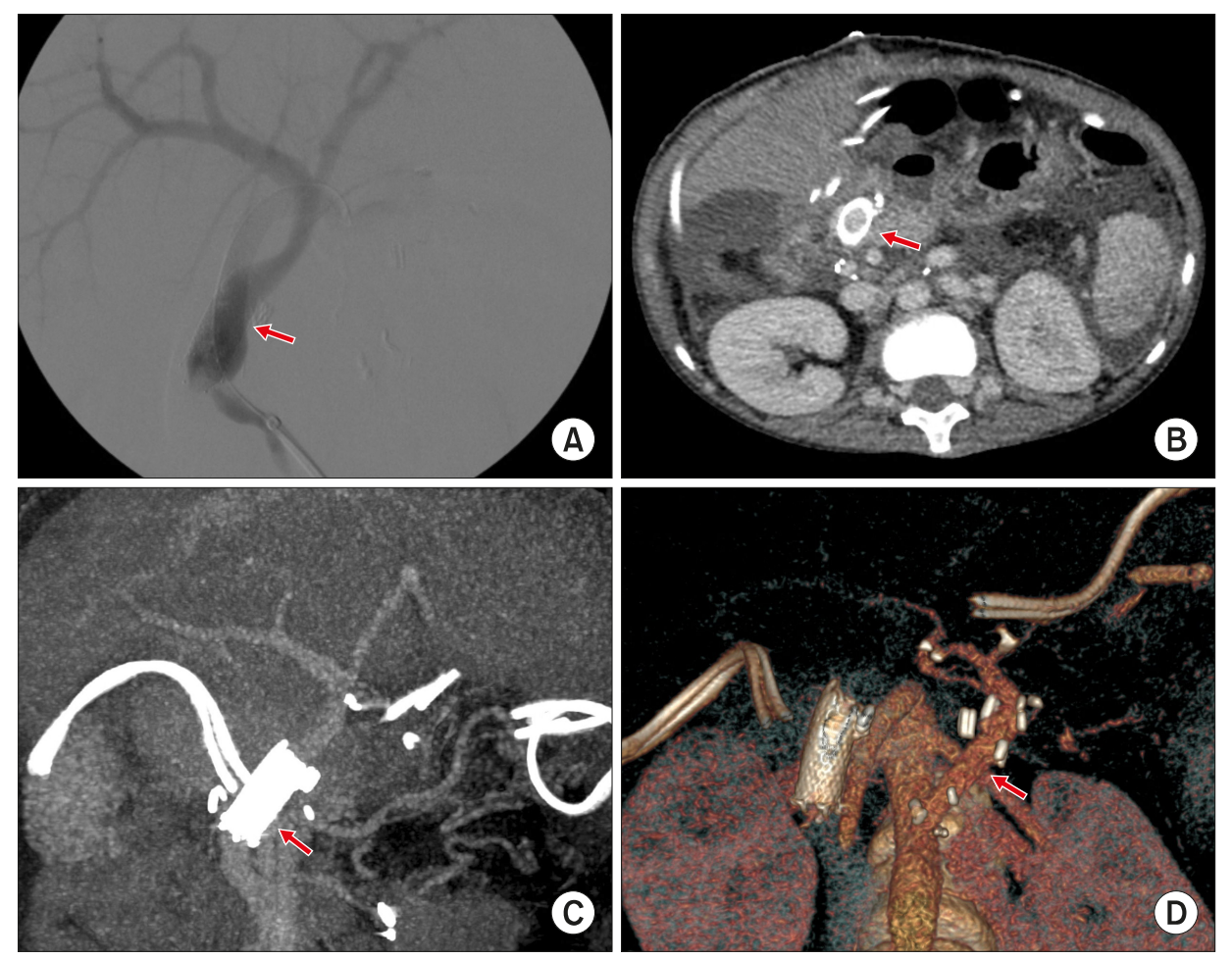

Fig. 8. Finding of the portal vein reconstruction following the third liver transplantation. (A) Direct intraoperative portogram shows portal vein flow passing well through the wall stent remnant (arrow). (B, C) Computed tomography taken 3 days after the third transplantation shows maintenance of portal vein flow through the wall stent remnant (arrows). (D) An aorto-hepatic jump graft is visible on the three-dimensional reconstruction image (arrow). 
nective tissues around the vascular structures are hardened through prolonged inflammation, often necessitating repetitive interventional procedures. ${ }^{2-6}$ Insertion of a self-expandable wall stent into the hepatic vein anastomosis is regarded as a life-saving procedure to cope with hepatic vein outflow obstruction, but risk of late retransplantation is possible because a vascular wall stent may not be expanded enough to accommodate the long-term physical growth of a patient from infancy to adolescence and adulthood. ${ }^{1}$

This case is a typical example of liver graft failure from wall stent-associated hepatic vein insufficiency. Soon after hepatic vein stenting, hepatic vein outflow obstruction was relieved. However, as the patient has grown up, the smallsized internal diameter of the stents could not drain the hepatic vein outflow effectively despite numerous sessions of balloon angioplasty, which induced progressive deterioration of graft function. To prevent such a catastrophic sequence, it is essential to perform evidence-based secure reconstruction to prevent the need for endovascular stenting during pediatric LDLT. A retrospective review of the present case revealed that the hepatic vein outflow obstruction was closely associated with the surgical techniques used in the infant LDLT. The surgical techniques for hepatic vein reconstruction of a left lateral section graft in an infant recipient should be different from those used in adolescent or adult patients. We have developed customized hepatic vein reconstruction techniques suitable for LDLT or split liver transplantation using a left lateral section graft in infant recipients. ${ }^{7,8}$

In the present case, the graft hepatic vein stump with an internal wall stent was heavily adhered to the diaphragm, making its dissection impossible. Thus, we had to transect the graft hepatic vein stump and securely repair it at the level of the diaphragm. The retrohepatic IVC was extensively dissected and isolated. Because of the small diameter of the retrohepatic IVC and absence of the native hepatic vein stumps, the usual modified piggyback anastomosis using a long triangular anastomosis was not feasible. Thus, graft outflow vein reconstruction was performed according to the typical double IVC method.

A wall stent was also inserted in the portal vein after the second LT. The portal vein stent was fully expanded to an external diameter of $1 \mathrm{~cm}$. The native portal vein was variant, being the preduodenal portal vein, due to bili- ary atresia polysplenia syndrome. ${ }^{9-12}$ Initially, we extensively dissected the superior mesenteric vein and adjacent collateral veins to isolate the stent-inserted portal vein-superior mesenteric vein junction portion, intending to remove the portal vein stent to prevent late stent-associated vascular complications. However, after transecting the stentcontaining portal vein, we found that the wall stent was heavily adhered to the portal vein wall, and its removal was impossible. Fortunately, because the wall stent was fully expanded with smoothly-formed neointima and its diameter was much larger than the graft portal vein, we decided to use the stent-containing portion for the portal vein anastomosis. Because the diameter of the portal vein stent appears to be comparable to that of small-sized adults, we presume that the remaining stent will not be a source of late portal vein insufficiency.

In the present patient, the right upper quadrant of the abdomen was collapsed with heavy adhesions and the left upper quadrant was expanded due to marked enlargement of the left lateral section graft, thus the normal shape of a whole liver graft was not well accommodated in the upper abdomen, even after extensive dissection of the right subphrenic fossa. To prevent abdominal compartment syndrome and extrinsic compression of the double IVC reconstruction, the transverse abdominal wound was temporarily closed with a xenograft patch for staged abdominal closure.

In conclusion, endovascular stenting of the hepatic or portal vein in young pediatric patients can induce vascular insufficiency, which can result in graft failure and late retransplantation, as shown in the present case. Consequently, we emphasize the importance of secure vascular reconstruction during LT in infant patients.

\section{ACKNOWLEDGEMENTS}

None of the authors was supported financially for this study.

\section{CONFLICT OF INTEREST}

None of the authors has any conflict of interest. 


\section{ORCID}

Jung-Man Namgoong: https://orcid.org/0000-0002-9237-7440

Shin Hwang: https://orcid.org/0000-0002-9045-2531

Young-In Yoon: https://orcid.org/0000-0002-9308-0366

Yong-Pil Cho: https://orcid.org/0000-0002-0639-451X

Woo-Hyoung Kang: https://orcid.org/0000-0002-3734-3352

Yong Jae Kwon: https://orcid.org/0000-0001-9490-1229

Hyunhee Kwon: https://orcid.org/0000-0001-6647-9155

Sang Hoon Kim: https://orcid.org/0000-0002-8025-1816

Kyung Mo Kim: https://orcid.org/0000-0001-7896-6751

Seak Hee Oh: https://orcid.org/0000-0002-9672-8877

\section{AUTHOR CONTRIBUTIONS}

Conceptualization: SH. Data curation: YIY, WHK, YJK, HK, SHK. Methodology: YPC, KMK, SHO. Visualization: SH. Writing - original draft: JMN, SH. Writing - review \& editing: All.

\section{REFERENCES}

1. Yeh YT, Chen CY, Tseng HS, Wang HK, Tsai HL, Lin NC, et al. Enlarging vascular stents after pediatric liver transplantation. J Pediatr Surg 2017;52:1934-1939.

2. Galloux A, Pace E, Franchi-Abella S, Branchereau S, Gonzales E, Pariente D. Diagnosis, treatment and outcome of hepatic venous outflow obstruction in paediatric liver transplantation: 24year experience at a single centre. Pediatr Radiol 2018;48:667679.
3. Katano T, Sanada Y, Hirata Y, Yamada N, Okada N, Onishi Y, et al. Endovascular stent placement for venous complications following pediatric liver transplantation: outcomes and indications. Pediatr Surg Int 2019;35:1185-1195.

4. Zhang ZY, Jin L, Chen G, Su TH, Zhu ZJ, Sun LY, et al. Balloon dilatation for treatment of hepatic venous outflow obstruction following pediatric liver transplantation. World $\mathrm{J}$ Gastroenterol 2017;23:8227-8234.

5. Lu KT, Cheng YF, Chen TY, Tsang LC, Ou HY, Yu CY, et al. Efficiency of transluminal angioplasty of hepatic venous outflow obstruction in pediatric liver transplantation. Transplant Proc 2018;50:2715-2717.

6. Kawano Y, Mizuta K, Sanada Y, Urahashi T, Ihara Y, Okada $\mathrm{N}$, et al. Complementary indicators for diagnosis of hepatic vein stenosis after pediatric living-donor liver transplantation. Transplant Proc 2016;48:1156-1161.

7. Namgoong JM, Hwang S, Park GC, Kwon H, Kwon YJ, Kim SH. Graft outflow vein unification venoplasty with superficial left hepatic vein branch in pediatric living donor liver transplantation using a left lateral section graft. Ann Hepatobiliary Pancreat Surg 2020;24:326-332.

8. Namgoong JM, Hwang S, Song GW, Kim DY, Ha TY, Jung $\mathrm{DH}$, et al. Pediatric liver transplantation with hyperreduced left lateral segment graft. Ann Hepatobiliary Pancreat Surg 2020;24: 503-512.

9. Davenport M, Tizzard SA, Underhill J, Mieli-Vergani G, Portmann B, Hadzić N. The biliary atresia splenic malformation syndrome: a 28 -year single-center retrospective study. J Pediatr 2006;149:393-400.

10. Broniszczak D, Apanasiewicz A, Czubkowski P, Kaliciński P, Ismail $\mathrm{H}$, Ostoja-Chyzynska $\mathrm{A}$, et al. Liver transplantation in children with biliary atresia and polysplenia syndrome. Ann Transplant 2011;16:14-17.

11. Nio M, Wada M, Sasaki H, Tanaka H, Watanabe T. Long-term outcomes of biliary atresia with splenic malformation. J Pediatr Surg 2015;50:2124-2127.

12. Namgoong JM, Hwang S, Kim DY, Ha TY, Song GW, Jung $\mathrm{DH}$, et al. Pediatric split liver transplantation in a patient with biliary atresia polysplenia syndrome and agenesis of inferior vena cava. Korean J Transplant 2020;34:286-292. 